\title{
LA POLÉMICA SOBRE EL HOMBRE TERCIARIO Y SU EXPRESIÓN EN LA VALENCIA DE COMIENZOS DEL SIGLO XX"
}

\author{
Jesús I. Catalá Gorgues
}

Universidad CEU Cardenal Herrera

\begin{abstract}
RESUMEN
El postulado por parte de algunos evolucionistas de finales del siglo XIX acerca de la antigüedad terciaria de la humanidad suscitó intensas polémicas entre naturalistas, biólogos y médicos. En España también hubo adherentes y detractores, cuyas diatribas entraban en el contexto general de la cuestión evolucionista en nuestro país. El debate se animó especialmente a raíz de la llegada a Valencia, en 1889, de un esqueleto humano fósil procedente de la Argentina al que se le atribuyeron rasgos primitivos y una gran antigüedad. A comienzos del siglo XX, una serie de publicaciones sobre dicho ejemplar reactivaron la polémica, con el catedrático de la Universidad de Valencia, Eduardo Boscá, como partidario de la atribución de edad terciaria, y con el antagonismo destacado ante tal propuesta del médico Faustino Barberá y de diversos científicos jesuitas. Datos científicos y argumentos ideológicos y religiosos se combinaron en la defensa de las posturas enfrentadas.
\end{abstract}

PALABRAS CLAVE: Evolucionismo. Paleoantropología. Hombre fósil. Valencia. España. Eduardo Boscá. Faustino Barberá. Jesuitas. Siglo XX

\section{THE CONTROVERSY REGARDING TERTIARY MAN AND ITS EXPRES- SION IN VALENCIA (SPAIN) DURING THE EARLY $20^{\mathrm{TH}}$ CENTURY}

\begin{abstract}
Postulates on the tertiary age of humanity by some late- $19^{\text {th }}$ century evolutionists gave rise to heated controversy among naturalists, biologists and physicians. In Spain, the diatribes between supporters and detractors must be located within the general context of the evolutionary subject in a country, that was deeply polarized by ideological impregnations. Spanish debate was specially
\end{abstract}

* Proyectos «Evolucionismo y los orígenes de la humanidad: la configuración de la paleoantropología como disciplina científica y su proyección en la biología española» (Ministerio de Educación y Ciencia, ref. HUM2006-04730), «Los años grises. La investigación biológica en la España del primer franquismo» (Ministerio de Ciencia e Innovación, I+D HAR 2010-21333C01) y «Ciencia, ideología y política en las sociedades naturalistas españolas del primer tercio del siglo XX» (Universidad CEU Cardenal Herrera, ref. PRCEU-UCH21/08). 
JESÚS I. CATALÁ GORGUES

motivated by the arrival in Valencia of a human skeleton fossil in 1889. This specimen, collected in Argentina, showed some peculiar traits that were classified as primitive and dating from the Tertiary time period. During the early decades of $20^{\text {th }}$ century, a series of papers about that skeleton were published and the controversy was reactivated. On one side, we find Eduardo Boscá, natural history professor in the University of Valencia, as a partisan of Tertiary age; on the other, the physician Faustino Barberá and some Jesuit scientists. Scientific data and ideological and religious arguments were combined in the defence of each confronted view.

KEY WORDS: Evolutionism. Paleoanthropology. Fossil man. Valencia. Spain. Eduardo Boscá. Faustino Barberá. Jesuits. $20^{\text {th }}$ century.

\section{INTRODUCCIÓN}

En 1889, llegó a Valencia procedente de Argentina una colección de mamíferos fósiles que el ingeniero José Rodrigo Botet (1842-1915) regaló a la ciudad. Entre los ejemplares que integraban el fondo, se hallaba un esqueleto humano casi completo, procedente del arroyo de Samborombón, no muy lejos y al sur de Buenos Aires, que el paleontólogo argentino Florentino Ameghino (1854-1911), tras una inspección somera, había datado como del Plioceno y, por tanto, de época terciaria. Ya en Valencia, Juan Vilanova y Piera (18211893), catedrático de la Universidad Central (Madrid), refirió en la prensa local, a comienzos de 1890, los ejemplares más relevantes de la colección de Rodrigo, entre los que contaba, muy particularmente, el esqueleto humano en cuestión ${ }^{1}$. Vilanova, conocedor de los trabajos de Ameghino, discrepaba sin embargo de la atribución terciaria, pues asumía una identidad entre la formación diluvial pampeana y el lehm europeo $^{2}$, incuestionablemente cuaternario.

Vilanova visitó la colección guiado por el recolector de la misma, Enrique de Carles, en principio, el responsable de su montaje. De Carles, sin embargo, abandonó al poco tiempo Valencia, al declararse un brote de cólera ${ }^{3}$. Desde

1 Sobre el hallazgo, primeros estudios y valoración de Vilanova del esqueleto humano de Samborombón, v. CATALÁ, J.I. (2011), ¿Absolutamente sin cuidado?: Juan Vilanova y la polémica sobre el hombre terciario. Asclepio, 63 pp. 379-404, artículo que se relaciona íntimamente con el presente, y al cual remitimos para la revisión del estado de la cuestión sobre la antigüedad terciaria de la especie humana en el último tercio del siglo XIX.

2 Vilanova, J. (1892), L'homme fossile du rio Samborombón. En Congrès International des Américanistes. Compte-rendu de la huitième session tenue a Paris en 1890, pp. 351-352 [facsímil de 1968, Nedeln/Liechtenstein, Kraus Reprint].

3 Belinchón, M.; Micó, J.A.; SAlinas, A. (1993), J. Rodrigo Botet i el mon cientific valencià entre les dos Republiques (1873-1931), Valencia, Ajuntament de València, p. 26; Belinchón, M.; Peñalver, E.; Montoya, P.; Gascó, F. (2009), Crónicas de fósiles. Las 
ese momento, fuera de los traslados que la llevaron por diferentes lugares de la ciudad, como el desaparecido convento de San Gregorio - situado en pleno centro de la ciudad, en la calle de San Vicente, en el lugar ocupado actualmente por el Teatro Olympia ${ }^{4}$ — o un local municipal en el número 62 de la calle Ruzafa, entre 1890 y 1895 apenas se registra actividad en torno a la colección tras la marcha de Enrique de Carles ${ }^{5}$. No obstante, en 1891 la Corporación municipal había dispuesto la formación de una comisión «que ha de hacerse cargo de la colección Paleontológica», formada por seis miembros, dos de los cuales eran naturalistas ${ }^{6}$. Se trataba en un caso de Emilio Ribera Gómez (1853-1921), catedrático de historia natural del Instituto de Segunda Enseñanza de Valencia 7 . El otro era Eduardo Boscá Casanoves (1843-1924), jardinero mayor del Jardín Botánico de la Universidad de Valencia, a punto de ser nombrado catedrático de historia natural de la misma, y futuro protagonista principal de cuantas iniciativas se emprendieron para el montaje y estudio de los restos ${ }^{8}$. Nacido en Valencia, Boscá era desde hacía años uno de

colecciones paleontológicas del Museo de Ciencias Naturales de Valencia, Valencia, Ajuntament de València, p. 35.

4 Catalá, M.A.; Vega, S. (2007), Valencia 1900. El legado fotográfico de J. Martínez Aloy, Valencia, Ajuntament de València, p. 38.

5 Salinas, M.A. (2000), Un proyecto de instalación del Museo Paleontológico Rodrigo Botet de Valencia en la primera década del siglo XX. En BAtlló, J.; Fuente, P. DE LA; Puig, R. (coords.), Actes de les $V$ Trobades d'Història de la Ciència i de la Tècnica als Països Catalans, Observatori de l'Ebre, 11-13 de desembre de 1998, Barcelona, Societat Catalana d'Història de la Ciència i de la Tècnica, pp. 485-492.

6 [Oficio de la Alcaldía por el que se comunica a Eduardo Boscá su nombramiento como individuo de la comisión que ha de hacerse cargo de la colección paleontológica. Valencia, 23 de septiembre de 1891], Archivo del Museo de Ciencias Naturales de Valencia (AMCNV), serie Documentación de carácter administrativo, doc. 5.

7 Sobre Ribera, v. CATALÁ, J.I. (2000), Los cultivadores de la historia natural en Valencia (1909-1940), Valencia, Universitat de València [tesis doctoral inédita], pp. 98-100, y LÓPEZ PIÑERO, J.M. (2003), Estudio introductorio. En RiBERA, E., Elementos de Historia Natural, Valencia, Cátedra de Eméritos de la Comunidad Valencia, pp. iii-xlv [facsímil de la cuarta edición, Valencia, Manuel Alufre, 1893].

8 Sobre los trabajos de montaje de la colección y la labor al respecto de Boscá, es de referencia SALINAS, M.A. (2001), Las colecciones paleontológica y conquiológica del Museo Paleontológico J. Rodrigo Botet de Valencia: inventario faunístico, importancia científica, museística e histórica, Valencia, Universitat de València [tesis doctoral inédita]. Para la biografía y contribuciones científicas del personaje, v. CATALÁ, J.I. (2005), Eduardo Boscá y el cultivo de la historia natural en la Valencia de la Restauración. Actividades Científicas de la Real Academia de Medicina de la Comunidad Valenciana, 6, pp. 51-72, y especialmente CATALÁ, J.I. (2004), El desarrollo de una carrera científica en un contexto institucional 
los más destacados defensores del evolucionismo en su tierra natal. Fue en su época de estudiante de medicina cuando se inició, de la mano del catedrático de historia natural Rafael Cisternas (1819-1876), en el conocimiento de la evolución, de forma prácticamente clandestina. Posteriormente, durante sus años en Madrid para completar la carrera de ciencias y doctorarse - ya en pleno período revolucionario- estableció relaciones con algunos jóvenes naturalistas de ideas avanzadas y también proclives a la aceptación de las hipótesis evolucionistas. Tras obtener plaza de catedrático de historia natural de enseñanza secundaria y ocupar la cátedra del Instituto de Ciudad Real, Boscá realizó entre los años finales de los setenta y los primeros de los ochenta importantes estudios herpetológicos, gracias a los cuales se renovó y mejoró notablemente el conocimiento de los anfibios y reptiles ibéricos; en estos trabajos, que obtuvieron un amplio reconocimiento internacional, Boscá no dudó en asumir la teoría evolutiva y en incorporar una orientación biogeográfica a la práctica taxonómica en esos grupos ${ }^{9}$. Aunque en 1881 logró un permiso oficial especial para llevar adelante sus estudios de campo, a la postre, sin embargo, su situación como catedrático en Ciudad Real distaba de ser la ideal para desarrollar una carrera científica. Esto debió de pesar mucho en la decisión que tomó en 1883, que le llevó a aceptar la mencionada plaza de jardinero mayor en Valencia, aun a costa de renunciar a la cátedra. Las cosas no rodaron demasiado bien, sin embargo, si atendemos a las quejas retrospectivas que manifestó Boscá respecto a tal decisión y a la evidencia de su escasísima producción científica durante aquellos años. No obstante, en 1892 logró acceder a la cátedra de la Universidad y pudo así retomar su carrera

precario: el caso del naturalista Eduardo Boscá y Casanoves (1843-1924). Cronos, 7 (1), pp. 3-60, donde se ofrece una aproximación somera al caso que estudiamos detalladamente en el presente trabajo. Recientemente, cuando una primera versión de éste ya había sido remitida a la redacción de Asclepio, se ha publicado SALINAS, M.A. (2009), El esqueleto humano de la colección paleontológica «Rodrigo Botet» de Valencia y el debate sobre la antigüedad del hombre (1890-1928), Debats, 105, pp. 85-100; en tal artículo se omiten varias referencias relevantes para el tema, y se llegan a conclusiones discrepantes con los trabajos no citados. Con posterioridad, ha salido publicada una biografía de Boscá a cargo de la misma autora; V. SALINAS, M.A. (2011), Eduardo Boscá Casanoves, 1843-1924: un darwinista valenciano, Valencia, Consell de Valencià de Cultura.

9 Más detalles sobre la contribución herpetológica de Boscá, en FrAGA, X.A. (1990), A modernización da Taxonomia herpetolóxica a fins do XIX no Estado Español: as aportacións de Boscá e López SeoAne. Treballs de la Societat Catalana d'Ictiologia i Herpetologia, 2, 26-43, y SÁnchez ArTeagA, J.M. (2005), Eduardo Boscá Casanoves y la renovación taxonómica de los catálogos faunísticos en España durante el último tercio del siglo XIX. Asclepio, 57 (2), pp.81-108. 
investigadora, centrada ahora, por mor de su designación para la comisión antes mencionada, en la paleontología de vertebrados ${ }^{10}$.

Boscá, de hecho, asumió de facto la dirección de los trabajos relacionados con la colección paleontológica municipal. Ya en octubre de 1891 había preparado, basándose en la lista de de Carles, una relación de los esqueletos que, en número de diez, y por estar razonablemente completos, podían ser susceptible de montaje para su exposición ${ }^{11}$. Como efectivamente no se dotaba ni de lugar ni de condiciones adecuadas, el montaje no pudo avanzar en los años siguientes. Será en 1895, con fecha de 20 de noviembre, cuando la Comisión de Monumentos del Ayuntamiento de Valencia acuerde la creación de una comisión auxiliar técnica para cuantas cuestiones se relacionaran con la colección paleontológica, en la que una vez más estará Boscá ${ }^{12}$, quien en 1896 recibe el encargo de la alcaldía de trasladar la colección a un local más espacioso donde poder avanzar en el montaje. El inmueble elegido era el antiguo parador de San Pablo, que había sido propiedad de los jesuitas ${ }^{13}$, bastante alejado del núcleo urbano - lo que llevó a su uso como hospital de coléricos en varias ocasiones durante la segunda mitad del siglo XIX-, extramuros de la calle de Quart. A pesar de las carencias y de dicho aislamiento, fue allí donde Boscá, ya plenamente responsabilizado de la colección, inició su labor científica con ésta en el verano de 189714 .

No tardarían en llegar los primeros frutos en forma de publicaciones. Así, en la sesión científica del día 1 de marzo de 1899 de la Sociedad Española de Historia Natural, se leyó una nota remitida por Boscá acerca de la colección. Después de ponderar, muy al estilo de los naturalistas españoles de la época ${ }^{15}$, el servicio a la ciencia patria que supuso el legado de Rodrigo y el trabajo de de Carles debidamente combinados, lamentaba la situación de la colección,

10 CAtalá (2004).

11 BoscÁ, E. Notas sobre la Colección paleontológica que el Ingeniero D. José Rodrigo Botet regala a la ciudad de Valencia, obtenida en las exploraciones efectuadas en las provincias de Buenos Aires (República Argentina) por el naturalista D. Enrique de Carles y principiada a instalar por el mismo naturalista [manuscrito]. Valencia, 21 de octubre de 1891. AMCNV, serie Relaciones y listas de piezas del legado de Jose Rodrigo Botet, doc. 2.

12 Acta de la sesión de la Comisión de Monumentos celebrada el 20 de noviembre de 1895 , Archivo Municipal de Valencia (AMV), Actas de la Comisión de Monumentos, año 1895.

13 Catalá, Vega (2007), p. 70.

14 SALinas (2000).

15 Sobre el nacionalismo en la práctica de los naturalista españoles, v. CASADO, S. (1994), La fundación de la Sociedad Española de Historia Natural y la dimensión nacionalista de la Historia Natural en España. Boletín de la Institución Libre Enseñanza, 19, pp. 45-64. 
depositada en un lugar poco adecuado. De asumir la letra del escrito de Boscá, todavía no se había procedido a montar, sino que los trabajos iban más bien por reunir y ordenar los fragmentos que integraban cada ejemplar. Pasaba luego a describir los principales, siguiendo la denominación y ordenación que Karl von Zittel (1839-1904) había consagrado en su tratado de paleontología, la referencia para los paleontólogos evolucionistas de la época. Por ello, el último ejemplar del que se ocupaba Boscá era, precisamente, el esqueleto de Samborombón. Identificado como perteneciente al género Homo, pero sin ofrecer ninguna determinación específica, remarcaba en primer lugar su carácter indudablemente fósil, junto con el hecho de ser contemporáneo del resto de mamíferos fósiles de la misma localidad representados en la colección (entre otros, Megatherium, Hoplophorus y Macrauchenia). Se recordaba, por otro lado, que aunque el esqueleto estaba casi completo, sus piezas no se habían encontrado en conexión anatómica y estaban fragmentadas, y por ello su reconstitución sería una de las labores más arduas de cuantas se tenían que acometer. Boscá hacía memoria de algunos — no de todos - de los rasgos peculiares del ejemplar. Exponía, además, algunas inferencias ya más elaboradas, y en las que llegaba a contradecir algunos criterios de Ameghino; así, en primer lugar, deducía el sexo masculino ${ }^{16}$; en segundo, la dolicocefalia; este argumento, aunque contrario al primer dictamen de Ameghino, en realidad reforzaba el carácter primitivo del ejemplar; además, y en tercer lugar, Boscá especulaba sobre la posible ausencia de las apófisis inferiores en la cara posterior de la barbilla, lo cual podría tener repercusiones en la ausencia de músculos relacionados con la facultad del habla en los humanos modernos. Infería también un régimen alimentario, según el desgaste de las piezas dentarias, basado en la masticación de raíces con tierra mal separada ${ }^{17}$. Boscá, por

16 Un estudio paleopatológico moderno del esqueleto indica la probabilidad de sexo femenino a partir de las características pélvicas, aunque «los caracteres secundarios sexuales craneales encontrados delaten una musculatura potente más propia del sexo masculino, al igual que los del lado de la mandíbula». El estudio en cuestión también recoge la alteración en el número de vértebras, con un aumento de las lumbares a expensas de las sacras, y la perforación del esternón, excluyendo en ambos casos patologías; v. PuCHALT, F.J.; Villalaín, J.D.; BELINCHÓn, M. (1995), Restos esqueléticos precolombinos en el Museo Paleontológico de Valencia. En Proceedings of the IXth European Meeting of the Paleopathology Association (Barcelona, 1st - 4th September, 1992), Barcelona, Museu d'Arqueologia de Catalunya, pp. 295-299, cita en p. 295.

17 Boscá CASANOVES, E. (1899), Noticias sobre una colección paleontológica regalada al Excmo. Ayuntamiento de Valencia, Anales de la Sociedad Española de Historia Natural (Actas), 28, 82-90. Puchalt et al. (1995), p. 299, deducen que «la robustez de la mandíbula y 
tanto, sin declarar todavía el carácter terciario del ejemplar de forma explícita, acentuaba ciertos rasgos, por otro lado muy discutibles, para reforzar la impresión de primitivismo.

\section{LA ASUNCIÓN DE LA EDAD TERCIARIA DEL ESQUELETO POR BOSCÁ Y LAS PRIME- RAS OBJECIONES}

Aunque en su día se saludara su llegada, es bien cierto que la colección paleontológica había acabado por ser una gran desconocida entre los valencianos. En 1902, sin embargo, surgió la oportunidad de rescatarla del olvido, al acceder el Ayuntamiento a los deseos de la comisión organizadora de la conmemoración del cuarto centenario de la Universidad de Valencia, que tuvo lugar en dicho año, de montar una muestra abierta al público donde pudieran contemplarse algunos ejemplares. Según los datos que aporta Manuel Giner San Antonio, autor del libro-memoria de los fastos, por entonces Boscá ya había procedido a montar partes del gran megaterio y de otros cuatro ejemplares ${ }^{18}$. En esa misma obra, y entre los apéndices que incluía, apareció una «Relación de los principales ejemplares» de que constaba la colección, que aunque formalmente es obra del mismo Giner, hay que atribuir a Boscá, tanto por lo que aquel dice en el capítulo correspondiente a la colección, cuanto porque existe una separata conjunta de capítulo y apéndice en la biblioteca del Museo de Ciencias Naturales del Ayuntamiento de Valencia, depositario actual de la colección, dedicada de puño y letra de Boscá que firma como «recuerdo del autor» ${ }^{19}$. En el apéndice, por primera vez, aparece explícitamente referido el esqueleto de Samborombón como «El hombre del período terciario»; allí mismo, el ejemplar es calificado como «la perla de la colección» ${ }^{20}$. Con esta publicación, se abría el fuego para el episodio valenciano de la polémica sobre el hombre terciario.

la usura dentaria revelan un uso intensivo del aparato masticatorio bien sea por una alimentación con granos de arena o sílice, o bien por mascar pieles»».

18 GINER, M. (1906a), Exposiciones abiertas al público durante los días de la celebración de los festejos. Exposición Paleontológica. En GINER, M. (rec.), Crónica del IV centenario de la Universidad de Valencia, Valencia, Doménech, pp. 163-167.

19 Catalá (2000), p. 531.

20 GiNeR, M. (1906b), Relación de los principales ejemplares de que consta la colección paleontológica, regalada á Valencia por don José Rodrigo Botet, expuesta al público durante los días de la celebración de los festejos. En GINER, M. (rec.), Crónica del IV centenario de la Universidad de Valencia, Valencia, Doménech, pp. 279-283, cita en en p. 283. 
La expresión pública del carácter terciario del esqueleto humano de Samborombón llegó en un momento para el que se suele asumir desde hace tiempo que el gran debate sobre la evolución se había reconducido en España hacia ámbitos de discusión más restringidos a lo científico, al tiempo que se generalizaba una aceptación, incluso por parte de los cultivadores de la ciencia católicos, si no de los mecanismos darwinistas - por otro lado, muy contestados entonces en todo el mundo ${ }^{21}$-, sí del hecho evolutivo ${ }^{22}$; ello, sin embargo, no impedía que, en ciertos casos, sobre todo cuando se hacía llegar la idea de evolución a la opinión pública — pensemos en el homenaje a Darwin en la Universidad de Valencia en $1909^{23}$ - volvieran a rebrotar los enfrentamientos ${ }^{24}$. Por eso, una declaración tan explícita como la expuesta, a través de una obra además pensada para la divulgación, contando con la polarización de opiniones que seguía presidiendo cualquier discusión sobre el origen, antigüedad y evolución del hombre, no podía quedar sin ser respondida. Fue un conocido médico valenciano con notable proyección pública, Faustino Barberá y Martí (1850-1924), quien se aprestó a contestar a los que defendían la edad terciaria del esqueleto de la colección paleontológica, y particularmente, a Eduardo Boscá. Barberá, destacado otorrinolaringólogo, era un personaje muy activo, dotado de una singular capacidad de iniciativa tanto en el ámbito profesional —así, en 1889 fundó la Revista Valenciana de Ciencias Médicas, y en 1894 fue uno de los organizadores del Congreso Médico-Farmacéutico Regional-, como en el social — se implicó muy intensamente en la enseñanza de los sordomudos ${ }^{25}$ y participó en el gobierno del sanatorio de leprosos de Fontilles ${ }^{26}$ - , e incluso en el político - fue una figura de relieve del nacionalismo valenciano en cuanto mentor y presidente, des-

21 BOwler, P.J. (1985), El eclipse del darwinismo. Teorías evolucionistas antidarwinistas en las décadas en torno a 1900, Barcelona, Labor.

22 GLICK, T.F. (1969), La recepción del darwinismo en España en dimensión comparativa. Asclepio, 21, 207-214.

23 Glick, T.F. (1982), Darwin en España, Barcelona, Península, pp. 51-67.

24 De hecho, autores de referencia como NúÑEZ, D. (1977), El darwinismo en España, Madrid, Castalia, no admiten una normalización del debate evolucionista en nuestro país con el nuevo siglo. Una revisión sobre contribuciones recientes en esa línea, en CATALÁ, J.I. (2009), Cuatro décadas de historiografía del evolucionismo en España. Asclepio, 61, pp. 9-66.

25 Micó, J.A. (1996), Faustino Barberá y Martí (1850-1924), médico, historiador, político e introductor en España del «Método Oral Puro» para la enseñanza de los sordomudos. Quaderns d'Investigació d'Alaquàs, 15, pp. 31-42.

26 Comes, V.E. (2009), Fontilles (1909-2009). En Comes, V.E. (dir.), Cuidados y consuelos. Cien años de Fontilles, Valencia, Generalitat Valenciana, pp. 91-361. 
de finales de 1906, de la asociación regionalista València Nova, además de ser miembro de otras entidades valencianistas ${ }^{27}$ - Barberá sentía así mismo mucha afición por las ciencias naturales; de hecho, y según testimonio de José Rodrigo Pertegás ${ }^{28}$, Barberá había frecuentado el laboratorio micrográfico que en el Colegio de San José de Valencia había montado, ya a finales del siglo XIX, el jesuita Antonio Vicent (1837-1912). Allí, Barberá se dedicaría a estudiar las diatomeas valencianas, y produjo una memoria que nunca sería impresa ${ }^{29}$.

Barberá colaboró, ciertamente, con diversos proyectos de los jesuitas. Ya hemos dicho que se implicó, como miembro de la comisión facultativa, en la obra del sanatorio de Fontilles, una iniciativa impulsada por su amigo, el padre Carlos Ferrís (1854-1924), quien compartía además con él mismo la condición de miembro de la junta fundadora del Colegio de Sordomudos y de Ciegos de Valencia ${ }^{30}$. En un ámbito más estrictamente científico, se interesó vivamente por el trabajo como arqueólogo y prehistoriador de Julio Furgús (1855-1909), otro jesuita, éste del Colegio de Santo Domingo de Orihuela aunque de origen francés, a quien dedicó un recuerdo en la Revista Valenciana de Ciencias Médicas con motivo de su fallecimiento en enero de 1909 tras despeñarse en un paraje en los alrededores de Orihuela ${ }^{31}$. En la recogida de materiales para la redacción de este trabajo, por cierto, le auxilió el jesuita naturalista del Colegio del Salvador de Zaragoza, Longinos Navás (1858-

27 CuCÓ, A. (1971), El valencianisme polític, Barcelona, Lavínia.

28 Rodrigo Pertegás, J. [1924]. Discurso necrológico del Dr. Faustino Barberá Martí [ms], Archivo Rodrigo Pertegás (ARP), legajo Faustino Barberá, pp. 25-26. Este discurso tuvo lugar en el Centro de Cultura Valenciana. Una versión algo distinta es RODRIGO PERTEGÁs, J. [1924]. Necro-apología del Dr. Faustino Barberá, [ms], ARP, legajo Faustino Barberá, pp. 29-30. El Archivo de José Rodrigo Pertegás está depositado en el Instituto de Historia de la Medicina y de la Ciencia «López Piñero» de Valencia. Además, está digitalizado. Los documentos citados se encuentran reproducidos electrónicamente en FRESQUET, J.L.; LÓPEZ, M.L.; Catalá, J.I. (2002), Archivo Rodrigo Pertegás: Ros de Ursins, Pere Pintor, Jaume Roig, Faustino Barberá, Valencia, Universitat de València / Fundación Marcelino Botín [CDROM]. Por otro lado, una transcripción del fragmento donde se cita el vínculo de Barberá con el laboratorio del padre Vicent, en Micó (1996), p. 35.

29 [Nota bibliográfica], ARP, legajo Faustino Barberá. Digitalizado en FRESQUET et al. (2002).

30 [Carta de Fernando Ferrando a Julio Perales. Valencia, 18 de febrero de 1928], ARP, legajo Faustino Barberá. Digitalizado en FRESQUET et al. (2002).

31 BARBerÁ, F. (1909), Las víctimas de la ciencia. Revista Valenciana de Ciencias Médicas, 11, 81-90, 97-106, 113-124, 137-140, 157-160. Se trataba de una serie de entregas en las que reproducía pasajes de algunas publicaciones de Furgús sobre sus temas de estudio. La primera se abría con un esbozo biográfico del finado. 
1938) ${ }^{32}$, impulsor de la Sociedad Aragonesa de Ciencias Naturales ${ }^{33}$, en la cual se dio de alta Barberá en $1907^{34}$. Significativamente, su inscripción en la Real Sociedad Española de Historia Natural tuvo lugar bastante después, en 1914, tras ser presentado por el también jesuita Jaime Balasch Bosch (18691927), profesor de historia natural en el Colegio de San José35. El vínculo, pues, con la Compañía de Jesús, era intenso y venía de antiguo.

No es casual, pues, que Barberá se pronunciara en contra de la atribución de edad terciaria al esqueleto de Samborombón en una comunicación leída en el homenaje a Linneo que la Sociedad Aragonesa de Ciencias Naturales, a impulso de Navás, había organizado en Zaragoza en 1907, con motivo del segundo centenario del nacimiento del gran naturalista sueco, figura venerada por los antievolucionistas precisamente como máximo exponente del fijis$\mathrm{mo}^{36}$. En este trabajo, el autor ya dejaba claro desde el principio que iba a estudiar «de los objetos paleontológicos allí existentes, [...] el esqueleto de homo [sic] sapiens, atractivo singular y encanto fascinador de los hombres de estudio ${ }^{37}$. Por la descripción que da, sabemos que el esqueleto para entonces ya contaba con una vitrina acristalada propia, con fondo de felpa roja, sobre la que descansaban los huesos fósiles ordenados en disposición natural, pero sueltos $^{38}$; también, que las piezas habían sido consolidadas con baños de gela-

32 [Carta de Longinos Navás a Faustino Barberá. Zaragoza, 14 de febrero de 1909], ARP, legajo Faustino Barberá. Digitalizado en FRESQUET et al. (2002).

33 Desde 1919, Sociedad Ibérica de Ciencias Naturales.

34 Sociedad Aragonesa de Ciencias Naturales (1908), Catálogo de los señores socios de la Sociedad Aragonesa de Ciencias Naturales. Boletín de la Sociedad Aragonesa de Ciencias Naturales, 7, pp. 5-15.

35 Sección de Valencia (1914), [Sesión del 28 de enero de 1914]. Boletín de la Real Sociedad Española de Historia Natural, 14, pp. 93-95.

36 No debemos inferir necesariamente, sin embargo, que Barberá fuera antievolucionista. Según BALAguer, E. (1996), Medicina y política en la Valencia de la Restauración: la obra de Faustino Barberá Martí (1850-1924). Quaderns d'Investigació d'Alaquàs, 15, pp. 43-65, las clases de anatomía impartidas por Peregrín Casanova, el célebre difusor del evolucionismo en Valencia, «impregnaron profundamente las concepciones científicas de Barberá» (cita en p. 47).

37 BARBERÁ, F. (1907a), Nota relativa al esqueleto humano de la colección paleontológica Botet en Valencia. En Linneo en España, Zaragoza, Mariano Escar, pp. 505-516, cita en p. 505. El mismo trabajo, con pequeñas modificaciones en la introducción, se reprodujo en BARBERÁ, F. (1907b), Nota relativa al esqueleto humano de la colección paleontológica Botet en Valencia. Revista Valenciana de Ciencias Médicas, 9, pp. 305-313.

38 Dirá en su momento Boscá: «Obedeciendo más bien á la presión de ambiente popular, que por convicción propia, transigimos en restaurar aquellos huesos que, por ser pares, permiten el estudio de los detalles ausentes en unos mediante el compañero del otro lado. A lo que 
tina. El grueso del estudio era una descripción parte por parte de los restos, empezando por la calavera y terminando por los pies. Respecto a los caracteres singulares que tanto habían llamado la atención de otros investigadores, Barberá se pronunciaba categóricamente; no encontraba el agujero occipital «más hacia atrás de lo corriente», mientras que la perforación esternal la achacaba a una soldadura incompleta de los hemisternones, y la anomalía en el número de vértebras lumbares (una de más) como un defecto compensado con la vértebra sacra de menos que exhibía. Barberá intentó inferir la talla del individuo a partir de la medición de los huesos de la pierna. En cuanto al sexo, reconocía la dificultad de determinación, aunque se inclinaba por el femenino en razón de la delicadeza de las líneas de inserción muscular y la suavidad general de las formas. En cualquier caso, reconocía que la pelvis era muy reducida, hecho para el que cabía la interpretación de que la mujer en cuestión habría sido nulípara y fuertemente raquítica. El interés del ejemplar, por tanto, estaría en lo teratológico, no en el supuesto primitivismo. La conclusión hacía explícito el rechazo a la atribución de edad terciaria al esqueleto, puesto que la aparición de restos humanos en el mismo nivel estratigráfico que los de otros seres vivos no forzaba a considerarlos como coetáneos si se tenía en cuenta que se trataba de materiales de acarreo fluvial. Citaba abiertamente la publicación que firmara Giner, pero no daba a entender que fuera Boscá — en todo el texto, solamente lo había citado al principio, para agradecerle el permiso para acceder al material estudiado- el que inspirara la idea. Sí que mencionaba a Ameghino, como defensor de la existencia del hombre terciario, y a Vilanova, como detractor, aun reconociendo - en opinión que asumía también él mismo- que ya hubo condiciones ambientales adecuadas en el Terciario para la existencia de seres humanos ${ }^{39}$.

En la publicación no aparece cuándo estudió efectivamente Barberá los restos, aunque sabemos que contempló la colección - recordemos que no estaba abierta al público - en febrero de 1904, cuando, en calidad de presidente del Instituto Médico Valenciano, encabezó un grupo de socios de dicha

nos hemos opuesto, es á montarlos, tanto para dejar expedito su estudio, como para no comprometerlos en la operación. El esqueleto [...] ha quedado encerrado en una modestísima urna de cristal, y ordenados en lo posible sus huesos»; v. BosCÁ, E. (1910), El esqueleto humano fósil del arroyo de Samborombón (América del Sur). En ASOCIACIÓN EsPaÑOLA PARA EL Progreso de las Ciencias, Congreso de Zaragoza, Madrid, Eduardo Arias, vol. 4 (1. parte), pp. 221-235, cita en p. 231.

39 BARBERÁ (1907a). 
corporación que pasaron a verla en visita científica ${ }^{40}$. ¿Tenía pensado desde entonces publicar algo sobre el esqueleto, o su decisión vino a la postre por la publicación dos años después del libro de Giner con la declaración del carácter terciario? No tenemos de momento respuesta. Sí podemos decir que, pese a la rotundidad con que Barberá se expresaba, Boscá no se arredró, y fue incluso más allá en la defensa de su opinión.

\section{LA POLÉMICA SIGUE}

Eduardo Boscá necesitaba, aparte de lo dicho en una obra eminentemente divulgativa $\mathrm{y}$, en todo caso, con poca difusión potencial, como era el libro del cuarto centenario de la Universidad, argumentar ante la comunidad científica la importancia singular del esqueleto de Samborombón. Preparó, pues, un estudio específico que presentó en 1908 al Primer Congreso de la Asociación Española para el Progreso de las Ciencias, celebrado en Zaragoza. El foro, atendiendo a las circunstancias, era especialmente adecuado. Aquel año había tenido lugar la escenificación de la profunda fractura que dividía el colectivo de naturalistas españoles. Como hemos estudiado en otro trabajo ${ }^{41}$, Longinos Navás, animado por el éxito obtenido con el homenaje a Linneo, planteó a finales de 1907 la celebración de un congreso de naturalistas españoles (sería el primero con ese carácter) en Zaragoza al año siguiente, dentro del programa para la conmemoración del centenario de los sitios que sufrió la ciudad durante la Guerra de la Independencia. Comunicó su idea a la sección local de la Real Sociedad Española de Historia Natural, quien a su vez transmitió la iniciativa a la Junta Directiva central en Madrid. La alarma cundió entonces entre los círculos dominados por Ignacio Bolívar (1850-1944), catedrático de la Universidad Central, director del Museo Nacional de Ciencias Naturales y hombre fuerte de la historia natural española de la época. Dejar que una iniciativa así pudiera ser llevada a buen puerto por Navás, uno de los líderes de

40 El Instituto Médico Valenciano pide permiso para practicar una visita oficial de carácter científico, el día 17 de Febro. Corrt. ${ }^{\mathrm{e}}$. AMV, Expedientes de la Comisión de Monumentos, 2/1904.

41 CAtalÁ, J.I. (2003), Confessionalitat i laïcisme: La fundació de l'Asociación Española para el Progreso de las Ciencias. Afers, 18 (46), pp. 565-590. El anhelo de celebrar congresos científicos de rango nacional en España ya había sido manifestado por Juan Vilanova; v. Salavert, V.L.; Pelayo, F.; Gozalo, R. (2003), Los inicios de la prehistoria en la España del siglo XIX: Juan Vilanova y Piera y el origen y antigüedad del hombre, Valencia, Universitat de València / Fundación Marcelino Botín [CD-ROM], p. 28. 
los naturalistas periféricos españoles y representante conspicuo del sector más clerical - frente, precisamente, a Bolívar, siempre vinculado a los círculos de tradición institucionista-, era conceder mucho. Por ello, la Junta directiva de la Real Sociedad derivó la propuesta para que, a la postre, se impulsara un congreso general de todas las ramas científicas, al uso de los que impulsaban las asociaciones para el progreso de las ciencias en diferentes países europeos desde hacía, en algunos casos, casi un siglo. Aquello fue el inicio del proceso de constitución de la Asociación Española para el Progreso de las Ciencias, que efectivamente celebró su primer congreso en la capital aragonesa en el mes de octubre de 1908. Esta reunión científica representó, de alguna manera, la demostración de la capacidad de respuesta de los naturalistas de círculos oficialistas, de afinidades ideológicas liberales o republicanas, al reto lanzado por la alternativa conservadora y clerical. Ahora bien, ésta, con Navás a la cabeza, fue capaz a su vez de sacar adelante la propuesta que originalmente se había planteado, y Zaragoza fue también sede, aquel mismo mes de octubre pero dos semanas antes, del Primer Congreso de Naturalistas Españoles, que logró reunir un número de comunicaciones similar al que aglutinó la sección de ciencias naturales del de la Asociación.

Aunque hubo algún caso de doble participación, los naturalistas más significados de una y otra facción solo participaron en el congreso que les era más afín. Boscá, como ya hemos dicho y como era de esperar, participó en el de la Asociación. En su comunicación seguía a Ameghino en la caracterización estratigráfica del esqueleto, e incluso hablaba de «prejuicios históricos, consiguientes a la falta de datos geográficos» para denunciar la tendencia tradicional de situar el origen de la humanidad en el Viejo Mundo y no considerar relevantes al respecto los restos americanos ${ }^{42}$. Él, como adherente a las tesis ameghinianas, asumía que Sudamérica podía ser cuna de la humanidad.

En su comunicación, Boscá realizaba una revisión bibliográfica de lo que hasta entonces se había dicho del esqueleto, por lo que citaba a Hermann Burmeister (1807-1892), Ameghino, Vilanova (cuyos artículos en Las Provincias recordaba interesadamente para consignar que la posición algo retrasada del agujero occipital había sido apreciada por primera vez por aquél) y las Lecciones de Antropología de Telesforo de Aranzadi (1860-1945) y Luis de Hoyos Sainz (1868-1951) ${ }^{43}$. También, en una nota a pie, se ocupaba de la contribución de Barberá, para criticar algunas de las consideraciones que éste hacía, y especialmente la interpretación del orificio del esternón, pues

42 BosCÁ (1910), p. 222.

43 Para todas estas referencias, v. CATALÁ (2011). 
«este hueso ha merecido [en el artículo de Barberá] un grabado representándolo de tamaño natural, en el que aparece la numeración de sus piezas colocadas á la inversa, no como equivocación, sino como error de concepto razonado en el texto; con lo cual, resulta que la anomalía del orificio, que tanto le preocupó, queda mucho menos explicable teratológicamente estudiada que considerando el hueso como un esternón francamente simiano; todo lo cual sea dicho sin ánimo de ofender al compañero» ${ }^{44}$.

Pasaba luego Boscá a ofrecer sus propias interpretaciones de algunos de los rasgos peculiares del ejemplar, para lo que apelaba a la autoridad de Ameghino junto a la información que le suministraba el trabajo antropológico del holandés Herman ten Kate (1858-1931), discípulo de Paul Broca (18241880) y Paul Topinard (1830-1911), que realizó numerosos estudios sobre las poblaciones indias de diversos lugares de América ${ }^{45}$. En concreto, consultó el artículo de Kate sobre los antiguos habitantes de la región calchaquí, es decir, la zona noroeste de Argentina, en la vecindad de la frontera boliviana ${ }^{46}$. Boscá consideraba que el esqueleto de Samborombón presentaba un parecido general muy acusado con los restos que se estudiaban en dicho artículo, y destacaba las similitudes en la mandíbula inferior, el esternón perforado (un rasgo muy extendido, según Kate, entre diferentes tribus indias), la pelvis y algunos otros rasgos menos llamativos. En cuanto al problema de la extraña fórmula vertebral que exhibía el ejemplar de Valencia, estimaba Boscá que la vértebra lumbar suplementaria (así considerada, por cuanto él mantenía que el sacro sí presentaba las habituales cinco vértebras soldadas),

«representa un modelo de reducción orgánica, á juzgar por la pequeñez de la vértebra, comparada con las normales que la preceden, y que constituiría un obstáculo al proceso de la verticalidad actual del cuerpo humano, conquistada por nuestros antecesores. Entiendo que mejor que explicar el hecho como un caso anómalo comprendido entre los de exceso de vértebras sin compensación, habrá que considerarlo, siguiendo al doctor F. Ameghino, como un dato paralelo al de la multiplicación de las piezas óseas esternales.» ${ }^{47}$

44 Boscá (1910), p. 226.

45 Hovens, P.; HerlaAr, J. (2005), Indians of the Great Basin: The 1883 Fieldwork and Collection of Herman ten Kate, Leiden, Digital publications of the National Museum of Ethnology [http://www.rmv.nl/publicaties/16Grotebek/e/greatbasin.pdf].

46 KATE, H. ten, (1896), Anthropologie des anciennes habitants de la Région Calchaquie (République Argentine). Anales del Museo de La Plata (sección antropológica), 1, pp. 1-62.

47 Boscá (1910), p. 228. 
Así pues, nada de casos patológicos ni teratologías, sino caracteres que, considerados funcionalmente, no hacían sino reforzar el carácter ancestral del ejemplar. Esta interpretación funcional llevará a Boscá a interpretar el desgaste en los dientes como evidencia, ni más ni menos, que de «canibalismo, asignado como histórico á las razas indígenas americanas, y en particular á las de América del Sur, sea cual fuere el motivo invocado para justificarlo» ${ }^{48}$. Rasgos anatómicos eran fuente, por tanto, de interpretaciones culturales, algo que también aparecía, en ese mismo trabajo, cuando como de pasada hablaba de huesos fósiles de animales pertenecientes al mismo legado de José Rodrigo Botet que presentaban golpes de instrumentos o incluso «finas hendiduras, como producidas por punta de sílex» ${ }^{49}$. Una manera más, al margen de la estratigrafía, de demostrar la contemporaneidad del hombre con la fauna pampeana extinguida (un objetivo, como ya hemos avanzado ${ }^{50}$, que había marcado la trayectoria del propio Ameghino).

A la postre, tanto esto último, como el resto de evidencias presentadas por Boscá, pretendían sustentar la atribución de edad terciaria al esqueleto de Samborombón. Sin embargo, en toda la comunicación presentada en el Congreso de Zaragoza no aparece de forma expresa tal idea. En ningún momento, pues, se habla explícitamente de «hombre terciario». Boscá tampoco aventuraba a qué forma humana en concreto, de las consideradas por Ameghino, podría adscribirse aquel ejemplar que había llegado a sus manos. Es cierto que el argentino solamente había empezado a dar noticias de la existencia de restos caracterizados como Tetraprothomo argentinus en 1907, y hasta 1909 no publicaría los correspondientes a Diprothomo platensis. Sin embargo, los géneros en cuestión, junto a Triprothomo y Prothomo, ya habían sido propuestos por él mismo en 1884, con ocasión de la publicación de su esquema hipotético de la filogenia humana ${ }^{51}$. En todo caso, no hay ni tan siquiera men-

48 BosCÁ (1910), p. 230.

49 BOSCÁ (1910), p. 231.

50 CATAlá (2011).

51 V. PodgornY, I. (2001), La clasificación de los restos arqueológicos en la Argentina, 1880-1940. Primera parte: La diversidad cultural y el problema de la antigüedad del hombre en el Plata. Saber y Tiempo, 12, pp. 5-26, y Podgorny, I. (2005), Bones and Devices in the Constitution of Paleontology in Argentina at the End of the Nineteenth Century. Science in Context, 18 (2), pp. 249-283. Ameghino presentó en su trabajo de juventud Filogenia (1884) un programa de clasificación evolucionista a partir de la embriología, la paleontología y una anatomía comparada ampliada, que llevaría a una reconstrucción de las formas predecesoras tras la aplicación de ciertas «leyes naturales» y del tratamiento matemático de la afinidad entre los seres; v. al respecto ORIONE, J. (1987), Florentino Ameghino y la influencia de Lamarck 
ción por parte de Boscá de tales supuestos ancestros, no solamente en evitación de una osadía como la de pretender identificar genérica o específicamente el esqueleto de Samborombón, sino ni siquiera a título informativo. ¿Ocultaban estas omisiones una discrepancia por parte de Boscá de la propuesta filogenética de Ameghino o de su modo de proceder en las reconstrucciones genealógicas, aunque mantuviera su adhesión a la antigüedad terciaria del hombre? La manera en que Boscá entiende la evolución es de las más cercanas al darwinismo de cuantas se pueden encontrar entre los naturalistas españoles de la época, sobre todo en su aplicación a los estudios faunísticos ${ }^{52}$, aunque esté lejos de ser un darwinista absolutamente ortodoxo; así, como ya hemos razonado en otro trabajo ${ }^{53}$, era capaz de combinar en una misma apor-

en la paleontología argentina del siglo XIX. Quipu, 4 (3), pp. 447-471. De esta forma, se podría establecer un esquema genealógico hipotético, del que el registro fósil tal vez llegaría a dar demostración fáctica en algún momento, siquiera de alguna de sus partes (pues, en todo momento, tiene en cuenta cuán incompleto es ese registro). De ahí que no haya paradoja en el hecho de que Ameghino estableciera su filogenia humana en un período temprano de su producción y solamente al final de la misma aportara estudios detallados de presuntas formas ancestrales fósiles. Una historia general de las reconstrucciones filogenéticas y sus problemas (incluido el uso de los fósiles) en Bowler, P.J. (1996), Life's Splendid Drama: Evolutionary Biology and the Reconstruction of Life's Ancestry, 1860-1940, Chicago, The University of Chicago Press.

52 FraGA, X.A. (2002), La recepción del darwinismo por los naturalistas españoles del siglo XIX, un análisis general. En Puig Samper, M.A.; Ruiz, R.; Galera, A. (eds.), Evolucionismo y cultura. Darwinismo en Europa e Iberoamérica, Madrid, Junta de Extremadura / Universidad Nacional Autónoma de México / Doce Calles, pp. 249-265. Este autor matiza, sin negarla en absoluto, la asunción de los principios darwinistas de diversos autores, entre otros, Cisternas y Boscá. Una visión, por el contrario, más proclive a hacer de ambos darwinistas en el pleno sentido del término, en LÓPEZ PIÑERO, J.M. (2008), El darwinismo valenciano del siglo XIX y su fundamento histórico, Valencia, Consell Valencià de Cultura, pp. 137-146.

53 CATALÁ (2004). No parece coincidir tampoco con esta visión matizada del darwinismo de Boscá SALINAS (2009), p. 96-97, que habla de «su inquebrantable adhesión al pensamiento darwinista y su fe ciega en el infalible cumplimiento de los principios de la evolución tal y como los conoció, primero de la mano de su maestro Rafael Cisternas, y después, directamente, a través de la obra de Charles Darwin», además de declarar que «no albergo la menor duda de que Boscá vivió como un darvinista hasta el menor asunto de su vida», aludiendo con ello a su compromiso social, que hace coincidir con el pensamiento del propio Darwin según se expresaría en Descent of Man. Tal vez un cierto exceso de simpatía por el personaje de Boscá - al que se refiere como «el científico valenciano más brillante de la Restauración» (SALINAS, 2009, p. 86) - haga decir esto a la mencionada autora; sin embargo, si es coherente con lo que dice, de «ubicar en su tiempo y su lugar antes de emitir juicios de valor» a Boscá, debería no olvidar el propio contexto de interpretación del darwinismo en las 
tación la herencia de los caracteres adquiridos y la perfectibilidad de los organismos con la lucha por la vida. Por otro lado, Boscá fue un adelantado - en sus contribuciones herpetológicas - en la introducción en España del concepto de grupo natural, que marca una clara asunción genealogista ${ }^{54}$. Boscá, de alguna manera, es un buen ejemplo de la complicada amalgama de ideas que los naturalistas evolucionistas españoles solían pergeñar. Su vinculación a las iniciativas de la Institución Libre de Enseñanza ${ }^{55}$ le harían sin duda conocedor - aunque no necesariamente adherente - de la aceptación condicionada de las tesis de Darwin por parte de los krausistas — quienes rechazaban el materialismo implícito en ellas-, y de las versiones entre ortogenéticas y lamarckistas que algunos de aquéllos elaboraron ${ }^{56}$. No hay que olvidar que Boscá fue uno de los jóvenes que impulsaron en Madrid el Ateneo Propagador de las Ciencias Naturales, donde la presencia krausista era importante. En realidad, y pese a las críticas krausistas a Haeckel, la propia asunción del cambio direccional hacía plausible los esquemas genealógicos puramente hipotéticos, y por tanto no cabría esperar en Boscá una beligerancia al respecto en el caso de ser proclive a unos esquemas evolucionistas no puramente materialistas. De hecho, en su discurso en el homenaje a Darwin en la Universidad de Valencia (1909), invocaba, respecto a la inclusión del hombre en la evolución, «la unidad sintética y sin excepciones, á que se encaminan los conocimientos, como ideal que nos aproxime á lo absoluto, ese más allá del que tan distantes

últimas décadas del siglo XIX, tanto en la comunidad internacional, como en España; pueden consultarse para orientaciones diferentes, entre otras muchas obras, BOWLER (1985), BOWLER, P.J. (1988), The Non-Darwinian Revolution: Reinterpreting a Historical Myth, Baltimore, The Johns Hopkins Univeristy Press, RuSE, M. (1996), Monad to Man: The Concept of Progress in Evolutionary Biology, Cambridge (Mass.), Cambridge University Press, y GLIBOFF, S. (2008), H.G. Bronn, Ernst Haeckel, and the Origins of German Darwinism, Cambridge (Mass.), MIT Press; para el caso español, sigue siendo perfectamente utilizable GLICK (1982), y actualizaciones posteriores como las de NúÑEZ, D. (1996), Darwinisme espagnol. En TORT, P. (dir.), Dictionnaire du darwinisme et de l'évolution, París, Presses Universitaires de France, pp. 896-900, y Pelayo, F. (2008), Darwinism and Paleontology: Reception and Diffusion of the Theory of Evolution in Spain. En EnGELS, E.M.; GLICK, T.F. (ed.), The Reception of Charles Darwin in Europe. Volume II, London / New York, Continuum, pp. 386-399. Juzgamos algo peligroso, por otro lado, llevar la coherencia darwinista de Boscá, incluso, a aproximarlo a una especie de «darwinismo social» que, como es bien conocido — v. BROWNE, J. (2009), Charles Darwin. El poder del lugar, Valencia, Universitat de València- Darwin mismo rechazó.

54 SÁNCHEZ ARTEAGA (2005).

55 CATALÁ (2004),

56 SIMÓ, J. (2004), La Naturphilosophie en España. La recepción del evolucionismo en el entorno de la tradición krausista. Asclepio, 56 (2), pp. 197-222. 
nos encontramos» ${ }^{57}$; sin el materialismo absoluto de un Haeckel, hay no obstante una asunción monista para la vía del saber.

Boscá procuró dar al trabajo del congreso de Zaragoza una difusión amplia, puesto que dispuso el envío de copias a personajes de la talla de Arthur Smith Woodward (1864-1944), Eugène Dubois (1858-1940) o Louis Dollo $(1857-1931)^{58}$, entre otros ${ }^{59}$. A la vez, la asignación de edad terciaria al esqueleto se popularizó rápidamente entre los colegas españoles, en un momento coincidente con la aceptación favorable de las ideas de Ameghino por naturalistas como Eduardo Hernández-Pacheco $(1872-1965)^{60}$. Estaba previsto

57 BoscÁ, E. (1909a), [Discurso pronunciado en la velada celebrada en el Paraninfo de la Universidad el 22 de febrero de 1909, en homenaje a Darwin]. Tribuna Médica, 3 (13), 4-7, p. 5.

58 Woodward, que trabajaba en el British Museum, visitó la colección de Valencia en dos ocasiones, y Boscá le devolvió la visita en Londres en febrero de 1910. Dubois y Dollo fueron visitados por Boscá en los Museos de Haarlem y de Bruselas, respectivamente, en el curso del mismo viaje, pero un mes después; v. BoscÁ, E. (1911), Los Museos de París, Londres, Amsterdam y Bruselas. Anales de la Junta para Ampliación de Estudios e Investigaciones Científicas, 4 (1), pp. 1-61.

59 «Nota de los folletos remitidos al extranjero, del hombre de Samborombón». AMCNV, serie Documentos relacionados con los museos extranjeros, doc. 1. En la lista también aparecía el nombre de Armand Thévenin (1870-1918), asistente de Marcellin Boule (1861-1942) en el Muséum d'histoire naturelle de París y responsable del hallazgo de los restos de una mano fósil casi completa en la Chapelle-aux-Saints, al año siguiente (1909) del gran descubrimiento de los hermanos Bouyssonie; v. HuREL, A. (2005), La découverte de l'Homme fossile de la Chapelleaux-Saints (1908): Pratiques de terrain, débats et représentations des Néandertaliens. Organon, 34, pp. 97-118. Así mismo, estaba en la relación Paul François Hubrecht (1880-1929), geólogo de Amsterdam a quien Boscá conoció en el curso del viaje comentado en la nota anterior; v. BosCÁ (1911). Este naturalista era hijo de Ambrosius Hubrecht (1853-1915), zoólogo vivamente interesado por la filogenia de los primates, estudioso de los társidos (a los que consideró como plausibles correlatos del tipo ancestral de primate, anticipando en algunos puntos la teoría de Frederic Wood Jones) y contradictor de la interpretación de Dubois de Pitecanthropus erectus; v. Bowler, P.J. (1986), Theories of Human Evolution. A Century of Debate, 1844-1944, Baltimore, The Johns Hopkins University Press, p. 118.

60 Hernández-Pacheco, que fue pensionado por la Junta para Ampliación de Estudios e Investigaciones Científicas en 1911 y 1912 para realizar estudios de paleoantropología y paleozoología en diversas instituciones extranjeras, publicó, efectivamente, algunos trabajos con el fin de difundir la obra del argentino, según revela PELAYO, F. (2007), La evolución humana y su difusión en España en el marco de la JAE. Asclepio, 59, pp. 137-162. En esta línea, hay que situar una nota de julio de 1910 leída durante la sesión científica de ese mes de la Real Sociedad Española de Historia Natural, donde, al comentar un trabajo de Ameghino sobre Diprothomo platensis, afirmaba que éste «aduce, si no una prueba decisiva á la que no puedan hacerse algunas objeciones de detalle, por lo menos es justo reconocer que en su última Memoria ha avanzado mucho en favor de su teoría del hombre terciario»; v. HERNÁNDEZ- 
que el Segundo Congreso de la Asociación Española para el Progreso de las Ciencias tuviera lugar en Valencia en 1909, dentro del programa de actos vinculados a la Exposición Regional. Diferentes circunstancias, y principalmente los sucesos derivados de la Semana Trágica de Barcelona, con la ejecución de Francisco Ferrer Guardia y la caída del gobierno de Maura, vinieron a coincidir en el tiempo, con escasa antelación, con las fechas marcadas para la gran reunión científica, a finales de octubre y comienzos de noviembre; a esto, se sumó que el propio presidente de la Asociación no era otro que Segismundo Moret (1833-1913), encargado de formar gobierno precisamente tras la dimisión de Maura y sus ministros. Así pues, no hubo más opción que el aplazamiento, y el Congreso tuvo lugar finalmente en mayo de $1910^{61}$. Con independencia de esto, Boscá ya tenía listo el primer catálogo-guía de la colección paleontológica que, debidamente publicado por el Ayuntamiento, fue explícitamente dedicado, como rezaba su título, «al Congreso de Valencia de la Asociación Española para el Progreso de las Ciencias». Para entonces, una parte apreciable de la colección ya se podía contemplar en la que sería su sede, oficialmente «provisional», durante más de ocho décadas: el Almudín, bello edificio gótico en el centro de la ciudad, que aunque amplio, era en todo caso poco adecuado para exhibir la muestra, sobre todo a causa de su deficiente estado de conservación. En el catálogo, el esqueleto era considerado «de raza sudamericana desaparecida, análoga, por lo menos, á la que en su día pobló la región argentina, llamada Calchaquía, y desolada en tiempo de la conquista de América por los españoles $\rangle^{62}$. Boscá apelaba a la autoridad de Ameghino para decir que el yacimiento donde fue hallado fue considerado por éste «de terciario plioceno superior, lacustre», evitando en todo momento, sin embargo, el empleo de la expresión «hombre terciario» como también cualquier caracterización taxonómica. Añadía que los restos ocupaban una urna aparte en un extremo del salón de exhibición. Por su parte, la Guía de Valencia que se publicó en obsequio de los congresistas daba cuenta anónimamente ${ }^{63}$, entre las atrac-

PACHECO, E. (1910), El Diprothomo platensis.-Un precursor del hombre del plioceno inferior de Buenos Aires, por el Dr. Florentino Ameghino [comunicación verbal]. Boletín de la Real Sociedad Española de Historia Natural, 10, 311-316, cita en p. 316.

61 CATALÁ (2003).

62 BoscÁ, E. (1909b), Catálogo-guía de la colección paleontológica de J. Rodrigo Botet, dedicado al Congreso de Valencia de la Asociación Española para el Progreso de las Ciencias, Valencia, Sucesores de Emilio Pascual, p. 12.

63 Para la gran producción de guías de Valencia con motivo o en torno a la Exposición Regional de 1909, v. SolAz, R. (2002), Guía de las guías de Valencia (1700-1975), Valencia, Ajuntament de València, pp. 158-169. 
ciones de la ciudad, del «Museo Paleontológico» —así, con esa denominación-, que contenía, entre otros valiosos ejemplares, «el esqueleto humano, fósil del terreno terciario, según el sabio doctor J. [sic] Ameghino, de la República Argentina. Estos restos pertenecen a una raza muy inferior ya extinguida» ${ }^{64}$.

Apenas amagada en el Congreso de Zaragoza la posición de Boscá favorable a la consideración de terciario del esqueleto de Samborombón, y solamente algo más patente en las otras dos publicaciones comentadas, el catedrático valenciano realizó en 1910 dos viajes, uno a comienzos de año y otro en los meses finales, que le llevaron a estudiar materiales relacionados con los de la colección en París, Londres, Ámsterdam y Bruselas, por un lado ${ }^{65}$, y en Buenos Aires y La Plata, por otro ${ }^{66}$. Boscá fue acompañado por su hijo Antimo (1874-1950), catedrático de historia natural por aquel entonces en el Instituto General y Técnico de Teruel, del que posteriormente pasaría al de Castellón $\mathrm{y}$, finalmente, al de Valencia, y excelente fotógrafo ${ }^{67}$. Para realizar tales periplos, los Boscá contaron con una pensión de la Junta para Ampliación de Estudios e Investigaciones Científicas ${ }^{68}$. En el Museo de Buenos Aires pudieron estudiar - pese a estar cerrado al público por amenazar ruina, y pese a estar un gran número de ejemplares embalados o metidos en cajas en previsión de un inminente traslado- diversos esqueletos fósiles de los que extrajeron datos para su comparación con los de Valencia. Se entrevistaron también con Enrique de Carles, quien les facilitó nuevos datos inéditos sobre los ejemplares que en su día recolectara y a quien acompañaron en una excursión científica. Y con el propio Ameghino, «ocupado en la actualidad en el estudio de las formas humanas últimamente encontradas en los tranquilos sedimentos de

64 II Congreso de la Asociación Española PARA el Progreso de las Ciencias (1909), Guía de Valencia publicada en obsequio a los señores congresistas, Valencia, F. Vives Mora, pp. 167-168. El texto sobre el Museo era idéntico al de la guía Valencia y su región, publicada el mismo año de 1909 por el Comité Ejecutivo de la Exposición; v. BELINCHÓN et al. (2009), p. 38, y SALINAS (2009), p. 94. En este último trabajo, se atribuye plausiblemente la autoría del texto a Boscá.

65 BosCÁ (1911). V. notas 59 y 59.

66 Boscá Casanoves, E.; Boscá Seytre, A. (1915), Los Museos Nacionales de Buenos Aires y de la Plata. Anales de la Junta para Ampliación de Estudios e Investigaciones Científicas, 8 (1), pp.1-65.

67 Algunos datos sobre Antimo Boscá, en CAMARASA, J.M.; CATAlÁ, J.I. (2008), Els nostres naturalistes. Volum II, València, Universitat de València, passim y especialmente p. 280.

68 Sobre la Junta como impulsora de los estudios sobre evolución humana, v. PELAYo (2007), donde se aportan también detalles sobre los viajes de los Boscá en tal contexto. 
la formación pampeana», pudieron revisar diversos materiales interesantes para las comparaciones con el esqueleto de Samborombón. En el Museo, por otro lado, hicieron acopio de bibliografía, y entre otros, de numerosos trabajos de Ameghino. También recibieron los valencianos una acogida formal en el Museo de la Plata, donde a su vez estudiaron diversos fósiles y se entrevistaron con Santiago Roth (1850-1924), jefe de la sección de paleontología y gran estudioso de la formación pampeana ${ }^{69}$, y Robert Lehmann-Nitsche (1872-1938), jefe de la sección de antropología. Éste, conocido por sus estudios lingüísticos y etnológicos, era también coordinador de un importante volumen sobre la formación pampeana — publicado en 1907 pero del que, aparentemente, Boscá no tenía noticia con ocasión del Congreso de Zaragoza de 1908 - de cuya parte antropológica se encargó personalmente ${ }^{70}$. Lehmann-Nitsche, un estudioso que realizaba su trabajo desde una perspectiva evolucionista, se manifestaba también contrario a la propuesta estratigráfica de Ameghino y, desde luego, mantenía que

«tous les restes ostéologiques humaines de la formation pampéenne actuellement entre nos mains, appartiennent [...] à l'Homo sapiens typique et que quelques unes des particularités ostéologiques de ce dernier se recontrent chez les indiens modernes» ${ }^{71}$.

Por otra parte, al ocuparse del esqueleto de Samborombón, y después de dar cuenta de las noticias y datos aportados en sus publicaciones por Burmeister, Ameghino y Vilanova, y verbalmente por Enrique de Carles, volvía a destacar la anomalía en la fórmula vertebral, como rasgo cierto de inferioridad, más la perforación esternal y el desgaste de las coronas dentales, como característica presente entre los indígenas sudamericanos actuales. Y como conclusión, señalaba que

69 Nacido Kaspar Jacob Roth — era suizo-, fue un activo estudioso de la paleontología argentina de la época y descubridor de importantes ejemplares, entre otros, el hombre fósil de Pontimelo; más detalles en Giacchino, A.; Gurovich, Y. (2001), Homenaje al Dr. Santiago Roth a 150 años de su natalicio. Agora Philosophica. Revista marplatense de Filosofia, 2 [consultada en internet en la página de la Fundación de Historia Natural Félix de Azara, 9 de julio de 2009: http://www.fundacionazara.org.ar/Artic/Tecnicos/fa057.htm].

70 Lehmann-Nitsche, R. (1907), Partie anthropologique. En LeHMAnN-Nitsche, R., (publ.), Nouvelles recherches sur la formation pampéenne et l'homme fossile de la République Argentine. Revista del Museo de la Plata, 14, pp.191-453.

71 LEHMANN-Nitsche, R. (1907), p. 203. 
«Une étude complète des restes de l'homme pampéen qui sont allés s'echouer au Musée de Valence, me paraît promettre des résultats intéressants, puisque, de son âge géologique, il n'y a pas lieu de douter» ${ }^{72}$.

No disponemos de momento de datos para juzgar si esta posición caló de algún modo en Boscá, pues nada comenta en el relato del viaje ni aparecen menciones posteriores a Lehmann-Nitsche ${ }^{73}$, quien, por otra parte, prodigó grandes atenciones a los valencianos durante su estancia e incluso les llevo de excursión para conocer in situ los sedimentos del Pampeano medio y superior $^{74}$. Desde luego, si atendemos a la noticia de una conferencia que impartió el 12 de agosto de 1915 en el propio Museo Paleontológico, acompañado de Antimo Boscá, siguió divulgando las ideas de Ameghino y, por tanto, el postulado de que «el hombre pampeano existía ya en la época terciaria», aunque, para el ejemplar depositado en Valencia, no podía «afirmarse que se trata del 'Homo pampeus' ${ }^{75}$. La fidelidad al paleontólogo argentino, desde luego, acabaría por ser acremente usada en su contra.

\section{LA CARGA DE LA BRIGADA JESUITA}

El empeño de Boscá por difundir su interpretación - la de Ameghino, en último término - de la antigüedad del género humano acabó por forzar la intervención del ala más beligerante de los antievolucionistas católicos. Como señala Glick, durante las primeras décadas del siglo XX, fue «una nueva generación de biólogos jesuitas» los que tomaron el relevo en la defensa del dogma, a partir de «una base más fundamentada científicamente que lo que les fue posible a sus antecesores» ${ }^{76}$. Por eso, no resulta extraño que, en no-

72 LeHMANN-Nitsche, R. (1907), p. 298.

73 Se conservan unas notas manuscritas de autor incierto sobre una cierta «conferencia» de Lehmann-Nitsche sobre el hombre fósil pampeano; desconocemos si se trata de unos apuntes tomados de una versión impresa o si realmente el autor asistió a una conferencia del mencionado especialista; v. Conferencia del Dr. Robert Lehmann-Nitsche. Sin fecha. AMCNV, serie Apuntes manuscritos de diversas caligrafias sobre los materiales, doc. 2.

74 BosCÁ y BosCÁ (1915).

75 Museo (1915), El Museo Paleontológico de Valencia. Una conferencia notable. Las Provincias, Valencia, 13 de agosto.

76 GLICK, T.F. (1992), El impacto del darwinismo en la Europa mediterránea y Latinoamérica. En Lafuente, A.; SAla, J. (eds.), Ciencia colonial en América, Madrid, Alianza, pp. 319-350, cita en p. 333. 
viembre de 1914, el jesuita Jaime Pujiula Dilmé (1869-1958), director del Instituto Biológico de Sarriá (Barcelona) y reputado embriólogo ${ }^{77}$, impartiera en el paraninfo de la Universidad de Valencia una serie de seis conferencias sobre «la vida y su evolución filogenética», dentro de los actos de la semana biológica que organizó el Instituto Médico Valenciano. La última de dichas charlas estuvo dedicada a la "Teoría de la descendencia», o de la evolución. Pujiula partía de una posición que solo admitía la probabilidad — que no certeza - de una evolución que él llamaba especigenética,

«una evolución moderada, según la cual las especies presentes serían en realidad modificaciones de otras especies o formas, no precisamente rudimentarias, sino tales que, bajo el influjo de leyes internas y evolutivas, se habrían ido modificando y adaptando a las circunstancias, adquiriendo unas mayor perfección y otras quizás más bien degenerando» ${ }^{78}$.

Pujiula, por otra parte, consideraba caduco el darwinismo, y veía con «más garantías de probabilidad» al lamarckismo. Basaba esta diferencia de valoración, sobre todo, en la negación de finalidad o en el carácter finalista, respectivamente.

Donde Pujiula resultaba absolutamente tajante era en defender la exclusión del hombre del proceso evolutivo ${ }^{79}$ :

«Actualmente se presenta la cuestión, en la mayor parte de las cátedras de Biología universitarias, como un hecho indiscutible. Ni es de extrañar; porque la mayor parte también de ellas son de hecho o por sistema ateas. Según ellas, el hombre es un producto de la evolución como otro cualquier organismo; es el último vástago de la evolución integral progresiva; es, digámoslo claro, aunque haga saltar los colores al rostro, una bestia perfeccionada. ¿Qué caída tan degradante para el hombre! ¡De origen divino a un vástago del bruto! Por fortuna queda aún gente sensata, que no ha doblado la rodilla ante el dios-materia, no sólo entre católicos, sino tam-

77 Un acercamiento a la vida y obra de Pujiula en Durfort, M. (1995), Jaume Pujiula i Dilmé, S.I (Besalú, Garrotxa, 1869-Barcelona, 1958), La morfologia microscòpica. En Camarasa, J.M.; RocA, A. (dirs.), Ciència i Tècnica als Països Catalans: una aproximació biogràfica, Barcelona, Fundació Catalana per a la Recerca, pp. 827-858.

78 PujIUla, J. (1915), Conferencias sobre la vida y su evolución filogenética esta última particularmente con relación al hombre dadas del 23 al 28 de noviembre 1914 en el paraninfo de la Universidad de Valencia a petición del Instituto Médico Valenciano, Barcelona, Tipografía Católica, pp. 160-161.

79 Desde la postura contraria, BosCÁ (1909a), p. 5, había señalado que «para muchos, el principal escollo del transformismo es el admitir sus conclusiones á propósito del hombre». 
bién entre acatólicos; gente que sabe volver por los fueros de la verdad y justicia, vindicando para el hombre los derechos de su dignidad y nobleza.» ${ }^{80}$

Lejos, pues, de la manera de conducirse de un Vilanova o incluso de un Barberá, que procuraban impugnar cuestiones relacionadas con la evolución humana mediante argumentos que no recurrían a consideraciones religiosas, Pujiula se lanzaba por la diatriba ideológica, con esa descalificación genérica a las cátedras universitarias y el colorido adjetival que se puede apreciar en la cita. Todo atisbo de lo que, siguiendo a Glick, podríamos denominar discurso civil sobre el evolucionismo ${ }^{81}$, estaba fuera de su consideración ${ }^{82}$.

Partía la crítica de Pujiula de que la reivindicación del origen del hombre en otros animales era blandida por zoólogos, incompetentes a la hora de juzgar de aquello «propio y característico del hombre»: el alma racional. Por otro lado, y aunque argumentativamente estaba dispuesto a «suponer posible la evolución y el origen animal del hombre, en cuanto al cuerpo» - lo que no deja de ser una concesión retórica a ese discurso civil- en realidad lo que deseaba probar es que ni la anatomía comparada ni la fisiología, como tampoco el recurso a los argumentos basados en los órganos rudimentarios, la embriología o la paleontología, podían ofrecer pruebas del origen animal del hombre. Al argumentar respecto a la paleontología, buena parte del esfuerzo de Pujiula se dedicó a probar la inconsistencia del postulado del hombre terciario, tanto desde el punto de vista de la hipótesis de los eolitos, como desde los argumentos en pro de subsumir dentro de la especie humana los restos relacionados con el hombre de Neandertal o el hombre de Java. Y naturalmente, también argumentó contra las hipótesis de Ameghino ${ }^{83}$, incluyendo en

80 PujiUla (1915), pp. 164-165.

81 GLICK, T.F. (1993), Ciencia, política y discurso civil en la España de Alfonso XIII. Espacio, Tiempo y Forma, Serie V, H. ${ }^{a}$ Contemporánea, 6, pp. 81-98.

82 No fue, de todos modos, el único autor en conducirse así, como muestra el caso del paleontólogo y profesor universitario Francisco Vidal y Careta (1860-1923), que juzgaba, con ocasión de la Primera Guerra Mundial, que el belicismo y el armamentismo, sobre todo por el lado alemán, conectaban con la asunción de las teorías de Darwin, al tiempo que arremetía contra la Institución Libre de Enseñanza y se burlaba de Ignacio Bolívar por sus enseñanzas evolucionistas; v. PELAYO, F. (2002), Darwinismo y antidarwinismo en España (1900-1939): la extensión y crítica de las ideas evolucionistas. En PUIG-SAMPER, M.A.; RUIZ, R.; GALERA, A. (eds.), Evolucionismo y cultura. Darwinismo en Europa e Iberoamérica, Madrid, Junta de Extremadura / Universidad Nacional Autónoma de México / Doce Calles, pp. 267-283.

83 Concretamente, contra su postulado de filogenia humana y contra la atribución de edad terciaria a restos humanos. No se ocupa, sin embargo, de las propuestas poligenistas de Ameghino, seguramente por haber excluido toda posibilidad de evolución humana. No hay 
el camino a Eduardo Boscá. El libro de Pujiula, también en este punto, representa un salto importante en el modo en que transcurría la polémica. Si Barberá, como hemos visto, trató de razonar sin personalizar en exceso y con moderación en sus expresiones, Pujiula, por el contrario, no dudó en emplear la ironía y hasta el sarcasmo para atacar a autores concretos:

«En las pampas de América se han encontrado esqueletos humanos que el Dr. Ameghino estimó o declaró como terciarios: Homo pampaeus, Tetraprothomo argentinus. Pero el sabio Dr. Ameghino, como le llama el Sr. Boscá, no ha podido convencer a las eminencias antropológicas de Europa, para quienes el Sr. Ameghino ha exagerado la antigüedad de las capas geológicas de las pampas, sin duda el único punto de apoyo, para hablarnos del hombre terciario. En opinión de Branca y demás antropólogos europeos de primer orden, ni las capas de las pampas son terciarias ni los esqueletos, en ellas encontrados, de otro que del Homo sapiens, en todo igual al de nuestros días. [...] este hombre terciario, lo más inverosímil de este mundo, pertenece al dominio de la imaginación. [...] Este es el juicio que se han formado los antropólogos de Europa de los trabajos científicos del Dr. Ameghino y el crédito que les merecen.» $\rangle^{84}$

No es baladí esa alusión a los especialistas europeos. La propuesta paleontológica de Ameghino fue desarrollada «en las condiciones de un país perifé-

que perder de vista que autores católicos como el cardenal Nicholas Wiseman se habían manifestado, antes incluso de las polémicas darwinistas, en contra del poligenismo, y que en ámbitos como el estadounidense, se vivía con más preocupación entre los católicos esta cuestión que la propia evolución darwinista; al respecto, v. LivingSTONE, D.N. (2000), The Origin and Unity of the Human Race. En Ferngren, G.B. (ed.), The History of Science and Religion in the Western Tradition: An Encyclopedia, New York / London, Garland Publishing, pp. 452457. Una evidencia de la posición contra el poligenismo desde perspectivas católicas durante la época que aquí se estudia, se puede encontrar en la revista Ibérica, editada por los jesuitas del Observatorio del Ebro y en la que Pujiula colaboraba con cierta frecuencia; concretamente, en una nota sobre el hallazgo del cráneo de Broken Hill en la colonia británica de Rodesia, se afirmaba por el autor anónimo que «no falta quien pretende haber visto en los caracteres de este cráneo, motivos para crear la especie Homo rhodesiensis, distinta de la Homo neanderthalensis, ni tampoco quien declare al individuo a quien perteneció, pariente más o menos próximo del Pithecanthropus erectus; pero en suma y prescindiendo de fantasías y errores, el cráneo de Broken Hill es completamente humano, y por sus caracteres no rompe la unidad específica de las diferentes razas humanas, como acabará de probarlo un estudio más detenido y completamente desapasionado»; v. HALLAZGO (1921), Hallazgo de un cráneo prehistórico. Ibérica, 16, 374-375, cita en p. 375.

84 PuJiUla (1915), pp. 191-192. 
rico» ${ }^{85}$. Pese a ello, como aquí estamos mostrando, sí halló eco favorable en científicos de otros países, en unos casos también periféricos - como el que ocupa nuestro interés - pero también centrales - por lo menos, en aquella parte relativa a la filogenia de los mamíferos-. Pujiula, en todo caso, explota el prejuicio al poner en contraste la propuesta de un sudamericano con la unánime opinión de los que trabajan donde se hacía ciencia de verdad.

\section{En cuanto al esqueleto de Valencia}

«Con esto queda también juzgado el esqueleto del arroyo de Samborombón, que se guarda en la colección de Rodrigo Botet, de esta ciudad (Valencia), y descrito en sus obras por el Dr. Ameghino» ${ }^{86}$.

Pasaba entonces a criticar, en concreto, la comunicación de Boscá («el ya jubilado catedrático de Ciencias Naturales de la Universidad de Valencia») en el congreso de Zaragoza, y se centraba al respecto en el argumento de «reducción orgánica» que empleaba para la vértebra lumbar supernumeraria. Pujiula entendía que no era un caso de reducción sino de multiplicación o división embrionaria de la vértebra en dos. Aducía la frecuencia de aparición de vértebras supernumerarias en personas actuales, «cuya explicación no se busca en la filogénesis como el Sr. Ameghino, a quien sigue el Sr. Boscá, sino en la Patología embriológica» ${ }^{87}$.

85 ORIONE (1987), p. 456.

86 Pujiula (1915), p. 192.

87 Pujiula (1915), pp. 193. En una edición posterior de esta obra, de 1925 —en la que, por cierto, sigue refiriéndose a Boscá como si estuviera vivo-, Pujiula añadía, en su filípica contra Ameghino, que «también lo ha dejado de vuelta y media en América (Buenos Aires) el P. José M. Blanco, S.J., en una serie de conferencias que dio en la Capital de la República Argentina»; v. PuJIULA, J. [1925], Conferencias sobre la vida y su evolución filogenética esta última particularmente con relación al hombre dadas del 23 al 28 de noviembre 1914 en el paraninfo de la Universidad de Valencia a petición del Instituto Médico Valenciano. Segunda edición revisada y puesta al día por el autor, Barcelona, Tipografía Católica Casals, pp. 187188. Sobre las críticas del jesuita José María Blanco a Ameghino, v. PoDGORNY, I. (1997), De la santidad laica del científico Florentino Ameghino y el espectáculo de la ciencia en la Argentina moderna. Entrepasados, 7, 37-61, así como ORIONE (1987) y BONOMO, M. (2002), El Hombre Fósil de Miramar. Intersecciones en Antropología, 3, pp. 69-85. Las querellas de Ameghino con sacerdotes, en todo caso y como es fácil de suponer, ya venían de mucho tiempo atrás. En concreto, cuando en 1884 publicó Filogenia, las iras clericales cayeron sobre él, si atendemos a lo que sostiene Gárate, J. (1970), Ameghino, Florentino. En Gillispie, C.C. 
La artillería jesuita siguió bombardeando en los meses siguientes. En octubre de 1915 se celebró en Valladolid el cuarto congreso de la Asociación Española para el Progreso de las Ciencias. El profesor de historia natural del Colegio de San José de Valencia, Jaime Balasch ${ }^{88}$, presentó una comunicación específicamente dedicada al esqueleto de Samborombón. Balasch declaraba al comienzo de su trabajo que éste estaba motivado por la «mera curiosidad» que le suscitaba «la insistencia con que he visto citar en algunas publicaciones españolas recientes un esqueleto fósil, que se conserva en la colección paleontológica de Valencia, como propio del terreno terciario» ${ }^{89}$. Tras citar tales publicaciones, concluía que, aun de diversos autores, el «inspirador» de tal idea no era otro que Eduardo Boscá, cuya conferencia en el verano anterior también recordaba. Efectivamente, entre las citas estaban las ya mencionadas Crónica del IV Centenario de la Universidad de Valencia y la guía Valencia y su región, publicada con ocasión de la Exposición Regional ${ }^{90}$, en las que no aparecía la autoría expresa de Boscá. También citaba Balasch obras firmadas por «el que fue Catedrático de Historia Natural de la

(ed.), Dictionary of Scientific Biography, New York, Charles Scribner's Sons, vol. 1, pp. 129132. La prensa argentina se mostró muy dividida tras la muerte de Ameghino respecto a la valoración de la obra de éste; v. la nota 38 de PODGORNY (1997), donde se reproduce una cita textual de La Cultura Argentina del año 1918; allí se caracteriza una corriente contraria a Ameghino que basaba sus críticas en lo científico, y otra, religiosa, a la que se acusaba de panfletista e irrespetuosa, y a la que en buena medida, cabe interpretar, representaba Blanco.

88 Un retazo biográfico de Balasch en PuJIUlA, J. (1927a), El R.P. Jaime Balasch, S.J., subdirector del Laboratorio Biológico de Sarriá y Secretario de la Sociedad Ibérica de Ciencias Naturales, Sección de Barcelona, fallecido el 9 de septiembre de 1927 (Nota necrológica). Boletín de la Sociedad Ibérica de Ciencias Naturales, 26, 147-150, aparecido también, con varios cambios y omisiones, en PUJIULA, J. (1927b), El R.P. Jaime Balasch, S.J. $\dagger$ Nota necrológica. Butlletí de la Institució Catalana d'Història Natural, 27, 129-130. La aportación científica de Balasch que más destaca Pujiula es, precisamente, su nota sobre el esqueleto de Samborombón. Sobre la actividad naturalista de Balasch en Valencia, v. Catalá, J.I. (1996), Los religiosos en la Sección de Valencia de la Real Sociedad Española de Historia Natural (1913-1936). En Real Sociedad Española de Historia Natural (XII Bienal), Tomo Extraordinario del 125 Aniversario, Madrid, Real Sociedad Española de Historia Natural, pp. 484-488. La fecha de nacimiento de Balasch, hasta ahora no reportada en los trabajos citados, en Catalogus (1919), Catalogus Provinciae Aragoniae Societatis Iesu Ineunte Anno MCMXX, Barcinone, Typis Eugenii Subirana, p. 80.

89 BALASCH, J. (1920), «Nota sobre el esqueleto humano fósil del arroyo de Samborombón (América del Sur)». En Asociación Española para el progreso de las ciencias, Congreso de Sevilla, Madrid, Eduardo Arias, vol. 6 (2. parte), pp. 63-71, cita en p. 63.

90 V. nota 64. 
Universidad de Valencia» como la comunicación en el Congreso de Zaragoza o el catálogo-guía de la colección. Llamativamente, incluía así mismo en la relación aquella nota aparecida en 1899 en los Anales de la Sociedad Española de Historia Natural, obra de Boscá pero en la que en absoluto se alude a la edad terciaria y en la que ni siquiera aparecen argumentos estratigráficos, fuera del reconocimiento de la contemporaneidad con la fauna de mamíferos.

En su impugnación, en realidad poco original, Balasch utilizó argumentos anatómicos tomados de la bibliografía. Destacaba el uso que hacía de los datos de Herman ten Kate, por cuanto utilizó la constatación de la presencia relativamente frecuente de perforaciones esternales en los indios sudamericanos para mostrar que en modo alguno el agujero en el esternón del esqueleto depositado en Valencia era un rasgo de primitivismo. En realidad, lo que se demuestra con este ejemplo es cómo, por el doble énfasis de probar la antigüedad de la presencia humana en América del Sur y la continuidad racial con los indígenas actuales, los partidarios de estas ideas acababan por utilizar un argumento que resultaba más poderoso para la segunda que no para la primera de tales ideas, y que, a la postre, lo que hacían era debilitarlo ante los ataques de sus oponentes. Balasch también hizo uso de inferencias sobre el modo en que se halló el esqueleto junto a otros ejemplares de la colección. Para ello, utilizó el testimonio de Enrique de Carles, con especial incidencia en el carácter revuelto de los restos, sitos en terreno de aluvión. Por último, revisaba la bibliografía estratigráfica para hacer ver que la mayoría de especialistas se inclinaban por la datación cuaternaria del pampeano superior.

Puesto que al inicio de su exposición, Balasch hacía depender enteramente las afirmaciones de Boscá de las teorías de Ameghino, la conclusión era que, obviamente, éste estaba equivocado. Sin reservas, decía que Burmeister había calificado en su día a Ameghino de "aficionado pretencioso», y aducía testimonios de autores franceses y británicos — estrategia semejante a la de Pujiula - también contra las teorías del naturalista argentino. El último párrafo es casi solemne de tan rotundo:

«De todo lo que llevo expuesto, pues, se deduce: que ni las particularidades del esqueleto fósil del Arroyo del Samborombón, ni el modo cómo se le encontró, ni los terrenos de donde se le extrajo, ni la mayor y mejor parte de los geólogos permiten admitir que el esqueleto fósil humano del Arroyo de Samborombón sea de la época terciaria y, por consiguiente, tampoco la opinión que el Sr. Ameghino de él sustenta.» ${ }^{91}$

91 BALASCH (1920), p. 71. 
La comunicación de Balasch, desde luego, hacía trizas la postura de Boscá. No sabemos cómo reaccionaría éste. No está de más recordar que Balasch formaba parte desde comienzos de 1912 de la Comisión Técnica Consultiva para la colección paleontológica que la Comisión de Monumentos del Ayuntamiento de Valencia había constituido ${ }^{92}$; así pues, tendría acceso privilegiado a la colección y, de una u otra manera, establecería alguna relación con Boscá93. En cualquier caso, la publicación de la comunicación debió de pasar por algunos avatares, si atendemos a que no apareció en las actas del Congreso de Valladolid, sino en las del posterior de Sevilla, celebrado en 1917, y en las que aparece como presentada en la sesión del 9 de mayo de dicho año. No tenemos duda, sin embargo, de que Balasch la presentó en el primero ${ }^{94}$, por cuanto, en una nota sobre la participación de los socios de la Aragonesa de Ciencias Naturales en el Congreso de Valladolid, Longinos Navás destacaba que aquél «desvaneció con datos y razones apodícticas las aserciones de Ameghino que le daba antigüedad fabulosa [al esqueleto] y asentó que era ni más ni menos que el Homo sapiens L., del pleno cuaternario.» ${ }^{95}$

92 Nueva Comisión Técnica, AMV, Expedientes de la Comisión de Monumentos, 26/1912.

93 Algunos detalles más sobre esta relación, en CATALÁ (2004).

94 Aun así, tampoco aparece anunciada entre los «trabajos anunciados» de la sección de ciencias naturales en el programa del congreso; v. Asociación Española para el progreso de las ciencias (1915), Congreso de Valladolid. 17-22 octubre 1915 [programa], Madrid, Eduardo Arias.

95 NAVÁs, L. [firma como L.N.] (1915), La Sociedad Aragonesa de Ciencias Naturales en el Congreso de la Asociación Española para el Progreso de las Ciencias de Valladolid. Boletín de la Sociedad Aragonesa de Ciencias Naturales, 14, 231-232, cita en p. 232. Por otro lado, el contenido de la comunicación fue también publicado por la propia Sociedad Aragonesa en su revista; v. BALASCH, J. (1917), «Nota sobre el esqueleto humano fósil del arroyo de Samborombón (América del Sur)». Boletín de la Sociedad Aragonesa de Ciencias Naturales, 16, 243-253. Estas enrevesadas circunstancias para el trabajo de Balasch ya tratamos de aclararlas en nuestro estudio anterior, CATALÁ (2004). El no haber atendido debidamente a ellas ha llevado a SALINAS (2009), p. 100, a cometer un error a la hora de rescatar una fuente hemerográfica que Balasch reporta, relativa a la conferencia de Boscá a la que antes hemos aludido. Salinas dice haber consultado el diario Las Provincias, que cita Balasch, y no haber hallado noticia al respecto, al tiempo que maneja la idea de que hubo dos conferencias, una de las cuales, el 12 de agosto de 1917. La conferencia - solamente una - tuvo lugar, por el contrario, justo dos años antes, en 1915, con dos meses de antelación respecto a la celebración del Congreso de Valladolid de la Asociación Española para el Progreso de las Ciencias; ciertamente, BALASCH (1917) la cita equivocadamente como de 1914 (aunque a la vez refiere correctamente la fecha del número de Las Provincias donde fue reseñada); v. MuSEO (1915). 
Lo cierto es que, con independencia de los virulentos ataques de Pujiula y Balasch, la causa de Boscá era difícilmente sostenible, toda vez que la comunidad científica cada vez se mostraba más unánimemente en contra de las teorías del ya difunto Florentino Ameghino ${ }^{96}$, que a la postre, habían sido la principal inspiración y apoyo para Boscá. Así, una autoridad mundial del calibre de Arthur Keith (1866-1955) —un personaje, por otro lado, absolutamente comprometido con la interpretación evolutiva del origen del hombre-, en su referencial The Antiquity of Man de 1915, con elegancia típicamente británica, pero con absoluta contundencia, rechazaba de plano las dataciones de Ameghino, de paso que juzgaba la obra de éste, en su conjunto, como recorrida por «a lack of precision and of detail, and particularly a decided tendency to overestimate the antiquity of all the geological strata of the Argentine Republic» ${ }^{97}$. En España, por su parte, resultaría especialmente influyente la opinión de Hugo Obermaier (1877-1946), el cual, en la primera versión de El hombre fósil (1916), hacía suya la postura de que no cabía considerar la presencia humana en el Terciario de Sudamérica ${ }^{98}$; en esa obra, por cierto, citaba el ejemplar del Museo Paleontológico de Valencia. En Francia, finalmente, y por no multiplicar los ejemplos, Marcellin Boule ${ }^{99}$ dictaba un juicio implacable en 1923: «les théories générales d'Ameghino sont radicalement fausses et l'on n'a jamais trouvé dans l'Amérique du Sud le moindre débris d'un Hominien fossile différant des Hommes actuels», al tiempo que conminaba a los jóvenes naturalistas de Sudamérica a aportar «un esprit nouveau, dégagé de tous liens antérieurs, à la solution des problèmes si intéressants qui se posent dans leur pays» ${ }^{100}$.

No esperó Boscá, sin embargo, a leer esta última obra. En 1921, en el tomo conmemorativo del cincuentenario de la Real Sociedad Española de His-

96 Quedó, no obstante, un remanente de fieles ameghinianos, sobre todo en la propia Argentina, sacudida tras la muerte del naturalista por las disputas entre glorificadores y detractores de su figura; v. Podgorny (1997) y BonOMO (2002). Posteriormente, la labor de Ameghino ha sido reconocida; además de numerosos estudios al respecto y diversos homenajes en su memoria, es destacable que la revista oficial de la Asociación Paleontológica Argentina se denomine Ameghiniana.

97 KeITH, A. (1915), The Antiquity of Man, London, Williams and Norgate, p. 289.

98 OBermaier, H. (1916), El hombre fósil, Madrid, Junta para Ampliación de Estudios e Investigaciones Científicas / Museo Nacional de Ciencias Naturales (Memoria n.$^{\circ} 9$ de la Comisión de Investigaciones Paleontológicas y Prehistóricas), pp. 288-290.

99 Quien así mismo citaba el esqueleto de Samborombón, «actuellement au Musée de Valence (Espagne)»; v. Boule, M. (1923), Les hommes fossiles. Éléments de paléontologie humaine, Paris, Masson et $\mathrm{C}^{\mathrm{ie}}$, p. 443.

100 Boule (1923), p. 446-447. 
toria Natural, publicó un «Catálogo abreviado» de la colección paleontológica, un trabajo breve que se limitaba a una noticia introductoria - en la que se reiteraban algunas de las quejas sobre la escasa dotación económica que se había podido consignar a lo largo de los años a los trabajos de montaje y estudio de la colección, así como la importancia científica de ésta - más una lista de especies. La referencia al esqueleto era escueta pero bien clara: «Homo sapiens L., arroyo de Samborombón» ${ }^{101}$. Boscá, pues, admitía que el ejemplar, aun peculiar, correspondía a un hombre moderno, y ya no hablaría en lugar alguno de su edad terciaria ${ }^{102}$; admitir la pertenencia a nuestra especie del ejemplar suponía, de facto, apartarse de las tesis de Ameghino ${ }^{103}$. Boscá, aunque todavía publicaría alguna contribución monográfica sobre otros ejemplares de la colección, falleció en 1924 sin volver a ocuparse del esqueleto humano que tanta polémica suscitara en las décadas anteriores ${ }^{104}$.

101 BoscÁ, E. (1921), Catálogo abreviado de la Colección Paleontológica Sudamericana existente en Valencia. Memorias de la Real Sociedad Española de Historia Natural, tomo del $\mathrm{L}$ aniversario, 550-555, cita en p. 553.

102 En las versiones en inglés, alemán, francés e italiano, escritas a mano o a máquina, de una circular informativa que se pretendía enviar en 1923 a los «Centros docentes y Científicos de Europa» para dar a conocer los ejemplares principales de la colección paleontológica de Valencia, se reseñaba «Homo sapiens fosilis» [sic], aunque todavía se aludía a sus singularidades anatómicas como evidencias de una raza prehistórica. V. AMV, Expedientes de la Comisión de Monumentos, 26/1923.

103 SALiNAS (2009), p. 96, pretende que Boscá «no abandonó su posición inicial en relación con el esqueleto», y se basa al respecto en la aseveración de éste en BOSCÁ (1921) de que representaba una forma extinguida. Este aserto se entiende mejor si se repara en el epíteto subespecífico que, según decimos en la nota anterior, todavía aparecía en las diferentes versiones de la circular a los museos extranjeros preparada en 1923. Una cosa es admitir que se trataba de una raza desaparecida de Homo sapiens, de gran antigüedad, y otra pretender que esto casaba con el esquema ameghiniano que retrotraía el origen de la humanidad, que no la aparición de Homo sapiens, al Terciario.

104 Pocos años después de la muerte de Eduardo Boscá, su hijo Antimo presentó una comunicación en el Congreso de Cádiz de la Asociación Española para el Progreso de las Ciencias, en la que describía unas observaciones con rayos $\mathrm{X}$ de algunas de las piezas singulares del esqueleto de Samborombón, con el propósito de determinar su grado de fosilización; v. BoscÁ, A. (1928), Aplicación de los rayos X a la determinación del estado de fosilización. En Asociación Española para el Progreso de las Ciencias, Congreso de Cádiz, Madrid, Huelves y Compañía, 6, pp. 199-202. Para más detalles de este asunto, v. CATALÁ (2004). 


\section{CONCLUSIONES}

La polémica sobre la presunta edad terciaria del esqueleto humano fósil del arroyo de Samborombón, donado al municipio de Valencia por el ingeniero José Rodrigo Botet junto con el resto de ejemplares que conformaban su colección paleontológica, muestra hasta qué punto las tensiones acerca de todo aquello que tuviera que ver con el origen, antigüedad y evolución del hombre seguían siendo importantes y acusadas entre los naturalistas, biólogos y médicos españoles del cambio de siglo. Dicha polémica, que se inició en la última década del siglo XIX y recorre las dos primeras del XX, corresponde a un período donde, de alguna manera, se reconoce una menor virulencia en las discusiones sobre la cuestión evolucionista de lo sucedido hasta entonces y una reconducción de las mismas hacia el seno del colectivo de científicos españoles. Sin embargo, aunque la misma se fue sustanciando básicamente en la literatura científica - en contraste con las diatribas propias de las décadas de los setenta y ochenta del siglo XIX, llevadas en muchas ocasiones a otros ámbitos de expresión menos regulados-, no por ello se mostró libre de impregnaciones ideológicas notables. Los detractores de la atribución de edad terciaria al esqueleto en cuestión eran generalmente católicos activos - algunos, de vida consagrada - y alineados con sectores políticos conservadores, mientras que el principal argumentador a favor de dicha atribución, Eduardo Boscá, tenía una postura religiosa notablemente más laxa y posiciones políticas así mismo mucho más a la izquierda. Es de notar cómo fue aumentando, conforme pasó el tiempo, el tono crítico de los escritos de los contrarios, con una presencia creciente de los ataques personales, y sin embargo con un conjunto de argumentos que, sustancialmente, había cambiado poco desde las primeras contribuciones. El protagonismo, además, fue siendo asumido por naturalistas profesos en congregaciones religiosas - en concreto, miembros de la Compañía de Jesús-, lo cual puede interpretarse como una reacción ante la pretensión de extender los procesos evolutivos - cuyo hecho ya era ampliamente asumido por la mayoría de los naturalistas españoles en aquel momento, incluidos buena parte de los católicos practicantes - a la naturaleza humana. Del antievolucionismo general de los primeros años de la Restauración se había pasado a centrar el discurso en la imposibilidad e impertinencia de la evolución de la especie humana, que en el pensamiento de estos autores solamente podía ser resultado de la creación directa de la mano de Dios. Ante la extendida «laicización del discurso sobre el hombre» ${ }^{105}$, se opuso una argumentación en

105 TORT, P. (2000), Darwin y la laicización del discurso sobre el hombre. Asclepio, 52 (2), pp. 51-83. 
principio teológica, pero que buscaba bases, pruebas y discurso en la biología, para mantener el estatus privilegiado del ser humano en el plan divino, en un ejemplo más de las preconcepciones teóricas, sesgos ideológicos y pasiones personales que siempre acompañan a la reconstrucción científica del pasado humano ${ }^{106}$.

Recibido: 5 de diciembre de 2009

Aceptado: 20 de julio de 2010

106 Tattersall, I. (1995), The Fossil Trail. How We Know What We Think We Know about Human Evolution, New York / Oxford, Oxford University Press. 